\title{
ПРЕДПРИНИМАТЕЛЬСКИЕ РИСКИ В РК
}

Баймолдаева М. Т., к.э.н., дочент, Казахская Академия труда и сочиальных отночений, 2. Алматы, Казахстан

Абдигалиева Н. К., магистр, стариий преподаватель, Казахская Академия труда и сочиальных отношений, г. Алматы, Казахстан

\section{DOI: https://doi.org/10.31435/rsglobal_conf/25032021/7469}

Abstract. It is legally established that entrepreneurial activity is risky, that is, the actions of entrepreneurs in the conditions of established market relations, competition, the functioning of the entire system of economic laws cannot be calculated and implemented with complete certainty. Many decisions in entrepreneurial activity have to be made in conditions of uncertainty, when it is necessary to choose a course of action from several possible options, the implementation of which is difficult to predict.

Kеушоrds: предпринимательские риски, производственный риск, финансовый риск, диверсификачия, факторинг.

В условиях перехода к рыночной экономике меняются методы хозяйствования в результате многочисленных экономических реформ. В сознании людей должно утвердится понятие того, что такое бизнес. Бизнес часто определяют как деятельность, направленную на извлечение прибыли. Это, в первую очередь, коммерческая деятельность, или предпринимательская, которой занимаются частные лица, а также организации.

Под предпринимательским понимается риск, возникающий при любых видах предпринимательской деятельности, связанных с производством продукции, товаров и услуг, их реализацией; товарно-денежными и финансовыми операциями; коммерцией, а также осуществлением научно-технических проектов.

Риск присущ любой сфере человеческой деятельности, что связано с множеством условий и факторов, влияющих на положительный исход принимаемых людьми решений. Исторический опыт показывает, что риск не до получения намеченных результатов особенно стал проявляться при всеобщности товарно-денежных отношений, конкуренции участников хозяйственного оборота. Поэтому с возникновением и развитием капиталистических отношений появляются различные теории риска, а классики экономической теории уделяют большое внимание исследованию проблем риска в предпринимательской деятельности.

Однако опыт развития всех стран показывает, что игнорирование или недооценка хозяйственного риска при разработке тактики и стратегии экономической политики, принятии конкретных решений неизбежно сдерживает развитие общества, научно-технического прогресса, обрекает экономическую систему на застой. Вновь возникновение интереса к проявлению риска в хозяйственной деятельности связано с проведением в Казахстане экономической реформы. Хозяйственная среда становится все более рыночной, вносит в предпринимательскую деятельность дополнительные элементы неопределенности, расширяет зоны рисковых ситуаций. В этих условиях возникают неясность и неуверенность в получении ожидаемого конечного результата, а, следовательно, возрастает и степень предпринимательского риска.

Экономические преобразования, происходящие в Казахстане, характеризуются ростом числа предпринимательских структур, созданием ряда новых рыночных инструментов. В связи с процессами демонополизации и приватизации государство правомерно отказалось от единоличного носителя риска, переложив всю ответственность на предпринимательские структуры. Однако большое число предпринимателей открывают свое дело при самых неблагоприятных условиях. До конца 80-х годов казахстанская экономика характеризовалась достаточно стабильными темпами развития. Первыми признаками проявления кризиса явились негативные процессы в инвестиционной сфере (снижение ввода основных производственных фондов), результатом чего стало снижение объемов произведенного национального дохода, промышленной и сельскохозяйственной продукции. Нарастающий кризис экономики Казахстана является одной из причин усиления предпринимательского риска, что приводит к увеличению числа убыточных предприятий.

Значительный рост убыточных предприятий позволяет сделать вывод о том, что без учета фактора риска в предпринимательской деятельности не обойтись, без этого сложным 
является получение адекватных реальным условиям результатов деятельности. Создать эффективный механизм функционирования предприятия на основе концепции безрискового хозяйствования невозможно.

Анализ риска всегда связан с установлением тенденций изменения характера возможных потерь, обусловленных принятием решений в случае рисковых ситуаций. В основу анализа рисков легли три основных критерия Б. Берлимера:

- потери от риска, независимые друг от друга;

- потери по одному направлению из «портфеля рисков» не обязательно увеличивают вероятность потерь по-другому (за исключением форс-мажорных обстоятельств);

- максимально возможный ущерб не должен превышать финансовых возможностей участников.

Основными задачами анализа риска следует считать: определение уровня риска, т.е. область его действия по оценочной шкале; установление величины риска; сопоставление величины риска с уровнем надежности производственной системы.

Актуальность этой темы сложно переоценить. В последнее время не только в Казахстане, но и во всем мире предпринимательство развивается огромными темпами.

Итак, настоящий предприниматель должен не стремиться избегать риска, а знать его разумные пределы, руководствоваться не только здравым смыслом, но еще и экономическим анализом степени риска.

Понятие риска используется в целом ряде наук. Исследования по анализу риска можно найти в литературе по психологии, медицине, философии; в каждой из них изучение риска основывается на предмете исследования данной науки и, естественно, опирается на собственные подходы и методы. Такое разнообразие направлений исследования риска объясняется многоаспектностью этого явления.

Анализ многочисленных определений риска позволяет выявить основные моменты, которые являются характерными для рисковой ситуации, такие, как:

- случайный характер события, который определяет, какой из возможных исходов реализуется на практике;

- наличие альтернативных решений;

- известны или можно определить вероятности исходов и ожидаемые результаты;

- вероятность возникновения убытков;

- вероятность получения дополнительной прибыли.

Таким образом, категорию «риск» можно определить как опасность потенциально возможной, вероятной потери ресурсов или недополучения доходов по сравнению с вариантом, который рассчитан на рациональное использование ресурсов в данном виде предпринимательской деятельности. Другими словами, риск - это угроза того, что предприниматель понесет потери в виде дополнительных расходов или получит доходы ниже тех, на которые он рассчитывал.

Хотя последствия риска чаще всего проявляются в виде финансовых потерь или невозможности получения ожидаемой прибыли, однако риск - это не только нежелательные результаты принятых решений. При определенных вариантах предпринимательских проектов существует не только опасность не достичь намеченного результата, но и вероятность превысить ожидаемую прибыль. В этом и заключается предпринимательский риск, который характеризуется сочетанием возможности достижения как нежелательных, так и особо благоприятных отклонений от запланированных результатов.

Под предпринимательским понимается риск, возникающий при любых видах предпринимательской деятельности, связанных с производством продукции, товаров и услуг, их реализацией; товарно-денежными и финансовыми операциями; коммерцией, а также осуществлением научно-технических проектов.

Предпринимательский риск - это риск деятельности компании, обусловленный характером бизнеса. К основным его видам можно отнести производственный, коммерческий и финансовый (кредитный) риски.

Производственный риск - это риск, связанный с производством продукции, услуг, с осуществлением любых видов производственной деятельности. Причины возникновения производственного риска: возможное снижение предполагаемых объемов производства, рост 
материальных затрат, недовольство работников, ошибки менеджеров, уплата повышенных отчислений и налогов и др.

Коммерческий риск возникает в процессе реализации товаров и услуг, произведенных или закупленных предпринимателем. Причины коммерческого риска: снижение объема реализации продукции, повышение закупочной цены материальных ресурсов, непредвиденное снижение объема закупок, повышение издержек обращения, экономические колебания и изменения вкуса клиентов, действия конкурентов.

Финансовый риск возникает в сфере отношений предприятия с банками и другими финансовыми институтами. Причины финансового риска: высокая величина соотношения заемных и собственных средств, зависимость от кредиторов, пассивность капиталов, одновременное размещение больших средств в одном проекте.

Финансовый риск чаще всего проявляется в получении ущерба от следующих операций: кредитных, инвестиций, эмиссии ценных бумаг.

Для предприятий сферы производства и обращения принято различать следующие составляющие их финансового риска: кредитный, процентный, валютный, риск упущенной выгоды, инвестиционный риск, налоговый риск.

Под финансовым риском участнику рынка ссудных капиталов обычно подразумевают разновидность общеэкономических рисков, связанных с угрозой невыполнения обязательств клиентом из-за его несостоятельности.

При выборе конкретного средства разрешения финансового риска инвестор должен исходить из следующих принципов: нельзя рисковать больше, чем это позволяет собственный капитал; нельзя рисковать многим ради малого; следует предугадывать последствия риска. То есть всегда необходимо рассчитать максимально возможный убыток по данному виду риска, потом сравнить его с объемом капитала предприятия, подвергаемого данному риску, и затем сопоставить весь возможный убыток с общим объемом денежных средств. И только тогда возможно определить, не приведет ли данный риск к банкротству предприятия. Это и есть общая стратегия управления риском.

Предприниматель проявляет готовность идти на риск в условиях неопределенности, поскольку наряду с риском потерь существует возможность дополнительных доходов. Можно выбрать решения, содержащие меньше риска, но при этом меньше будет и получаемая прибыль. Более высокий риск связан с вероятностного извлечения более высокого дохода.

Следует заметить, что предприниматель вправе частично переложить риск на других субъектов экономики, но полностью избежать его он не может. Справедливо считается: кто не рискует, тот не выигрывает. Иными словами, для получения экономической прибыли предприниматель должен осознанно пойти на принятие рискового решения.

Можно с уверенностью сказать: неопределенность и риск в предпринимательской деятельности играют очень важную роль, заключая в себе противоречие между планируемым и действительным, то есть источник развития предпринимательской деятельности. Предпринимательский риск имеет объективную основу из-за неопределенности внешней среды по отношению к предпринимательской фирме. Внешняя среда включает в себя объективные экономические, социальные и политические условия, в рамках которых фирма осуществляет свою деятельность и к динамике которых она вынуждена приспосабливаться. Неопределенность ситуации предопределяется тем, что она зависит от множества переменных, контрагентов и лиц, поведение которых не всегда можно предсказать с приемлемой точностью. Сказывается также и отсутствие четкости в определении целей, критериев и показателей их оценки (сдвиги в общественных потребностях и потребительском спросе, появление технических и технологических новшеств, изменение конъюнктуры рынка, непредсказуемые природные явления).

Предпринимательство всегда сопряжено с неопределенностью экономической конъюнктуры, которая вытекает из непостоянства спроса-предложения на товары, деньги, факторы производства, из многовариантности сфер приложения капиталов и разнообразия критериев предпочтительности инвестирования средств, из ограниченности знаний об областях бизнеса и коммерции, и многих других обстоятельств.

Экономическое поведение предпринимателя при рыночных отношениях основано на выбираемой, на свой риск реализуемой индивидуальной программе предпринимательской деятельности в рамках возможностей, которые вытекают из законодательных актов. Каждый 
участник рыночных отношений изначально лишен заранее известных, однозначно заданных параметров, гарантий успеха: обеспеченной доли участия в рынке, доступности к производственным ресурсам по фиксированным ценам, устойчивости покупательной способности денежных единиц, неизменности норм и нормативов и других инструментов экономического управления.

Наличие предпринимательского риска - это, по сути дела, оборотная сторона свободы экономической, своеобразная плата за нее. Свободе одного предпринимателя сопутствует одновременно и свобода других предпринимателей, следовательно, по мере развития рыночных отношений в нашей стране будет усиливаться неопределенность и предпринимательский риск.

Устранить неопределенность будущего в предпринимательской деятельности невозможно, так как она является элементом объективной действительности. Риск присущ предпринимательству и является неотъемлемой частью его экономической жизни. До сих пор мы обращали внимание только на объективную сторону предпринимательского риска. Действительно, риск связан с реальными процессами в экономике. Объективность риска связана с наличием факторов, существование которых, в конечном счете, не зависит от действия предпринимателей.

Предприниматель оценивает ситуацию, формирует множество возможных исходов и представляет вероятности их осуществления, делает выбор из множества альтернатив. Кроме этого, восприятие риска зависит от каждого конкретного человека с его характером, складом ума, психологическими особенностями, уровнем знаний в области его деятельности. Для одного предпринимателя данная величина риска является приемлемой, тогда как для другого - неприемлемой.

Оценка риска и выбор решения во многом зависят от человека, его принимающего. Одна и та же рискованная ситуация характеризуется разными предпринимателями неодинаково, поскольку риск воспринимается сугубо индивидуально. Немало зависит от того, что возьмет верх - предчувствие успеха или неудачи. Рискованных решений обычно избегают предприниматели консервативного типа, не склонные к инновациям.

В принятии предпринимателем решения, связанного с риском, важную роль играет его информированность, опыт, квалификация, деловые качества. Предприниматель предрасположен к рискованным решениям в том случае, если уверен в профессионализме исполнителей. Также готовность идти на риск в немалой степени определяется под воздействием результатов реализации, предыдущих решений, принятых в тех же условиях. Ошибки, допущенные ранее в аналогичной ситуации, диктуют выбор более осторожной стратегии.

Деятельность предприятия так или иначе связана с риском. Задачей руководства предприятия является снижение степени риска. Для этого используются различные способы: диверсификация, страхование, лимитирование, резервирование средств на покрытие непредвиденных расходов, распределение риска, получение большей информации о предстоящем выборе и результатах.

Диверсификация - это распределение капиталовложений между разнообразными видами деятельности, результаты которых непосредственно не связаны. Предприятие, неся убытки по одному виду деятельности, может получить прибыль за счет другой сферы деятельности. Диверсификация позволяет повысить устойчивость предприятия к изменениям в предпринимательской среде. Оптимальным считается одновременное финансирование 10-15 проектов, что позволяет рассредоточить риск. В резерве для возможных дополнительных выплат на более поздних этапах развития того или иного предприятия фирма держит 10-20\% суммы фонда. Для дальнейшего снижения риска практикуется совместное финансирование проектов силами нескольких частных фирм "рискового капитала".

Лимитирование предполагает установление лимита, т.е. определенных сумм расходов, продажи товаров в кредит, сумм вложения капитала и т.п.

Резервирование средств на покрытие непредвиденных расходов предполагает установление соотношения между потенциальными рисками и размерами расходов, необходимых для преодоления последствий этих рисков. Такой способ снижения рисков обычно используют при выполнении различных проектов. В общем случае резерв используется для финансирования дополнительных работ, компенсации непредвиденных изменений материальных и трудовых затрат, накладных расходов и других затрат, возникающих в процессе осуществления проекта. 
Распределение риска предполагает разделение риска между участниками проекта. Рост размеров и продолжительности инвестирования, внедрение новых технологий, высокая динамичность внешней среды увеличивает риск проекта. Способом разделения риска являются операции факторинга. В практике зарубежных банков развитие факторинговых операций связано главным образом с потребностью отдельных поставщиков в ускоренном получении платежей, которые представляются сомнительными. Как правило, в этих ситуациях имеет место риск неуплаты претензий плательщиком вообще. Банк, выкупивший, такие претензии у поставщика в этом случае может понести убытки. Операции факторинга относятся к операциям повышенного риска. Размер комиссионного вознаграждения зависит как от степени риска (от уровня «сомнительности» выкупаемого долга), так и от длительности договорной отсрочки. В некоторых случаях он доходит до $20 \%$ от суммы платежа.

Любое управленческое решение принимается в условиях, когда результаты не определены и информация ограниченна. Следовательно, чем полнее информация, тем больше предпосылок сделать лучший прогноз и снизить риск. Стоимость полной информации рассчитывается как разность между ожидаемой стоимостью какого-нибудь мероприятия (проекта приобретения), когда имеется полная информация, и ожидаемой стоимостью, когда информация неполная.

Риски воздействуют на различные стороны работы предприятия и, как правило, воздействие это носит негативный характер. Особенно вредно присутствие и влияние фактора риска на предприятие, уже находящегося в кризисе. Работу по стабилизации положения необходимо начинать с управления рисками, то есть разрабатывать и внедрять экономически целесообразные для предприятия рекомендации и мероприятия, направленные на уменьшение финансовых потерь, связанных с риском.

Любое предприятие, заинтересованное в снижении возможных потерь, связанных с экономическим риском, должно решить для себя несколько проблем:

- оценить возможные убытки, связанные с экономическими рисками;

- принять решение о том, оставляет ли она у себя определенные риски, т. е. несет ли всю ответственность по ним сама, отказывается от них или передает часть или всю ответственность по ним другим субъектам;

- по тем рискам или той части рисков, которые она оставляет у себя, фирма должна разработать программу управления ими, основной целью которой является снижение возможных потерь.

Решение этих задач возможно на основе разработки специальной программы целевых мероприятий по управлению риском (далее в тексте - ПЦМ) на уровне предприятия. Разработка подобной программы на уровне предприятия должна обеспечивать такое управление рисками, при котором основным элементам структуры и деятельности фирмы гарантируются высокая устойчивость и защищенность от внутренних и внешних экономических рисков.

\section{ЛИТЕРАТУРА}

1. Послание Президента РК «О предпринимательстве» 2020г.

2. Мальцева Е., Савкина Р. Организация предпринимательской деятельности: Учебное пособие. М.: Кнорус, 2011. - 216 с.

3. Савицкая, Г.В. Анализ эффективности и рисков предпринимательской деятельности. Методологические аспекты. Монография / Г.В. Савицкая. - М.: ИНФРА-М, 2017. - 943с. 